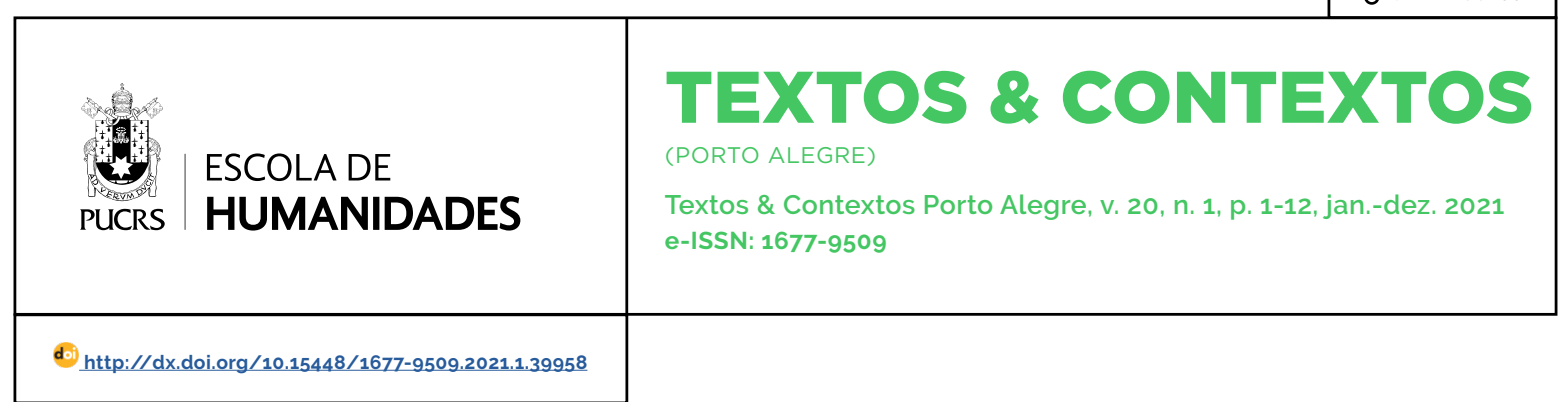

SEÇÃO: ARTIGOS E ENSAIOS

\title{
A saúde pública para além do debate entre direito e meritocracia ${ }^{1}$
}

\author{
Public health beyond the debate between law and meritocracy
}

Rosa Maria Marques
orcid.org/0000-0002-5624-0885
rosamkmarques@gmail.com

\section{Marcel Guedes Leite ${ }^{2}$}

orcid.org/0000-0001-9305-9703

marcel.leite@pucsp.br

\section{Marcelo Álvares de \\ Lima Depieri3}

orcid.org/0000-0002-2175-2098

cellodepieri@gmail.com

Recebido em: 18 jan. 2021.

Aprovado em: 3 ago. 2021.

Publicado em: 5 nov. 2021.
Resumo: Este artigo discute a ressignificação de parte da saúde pública a partir da realidade posta pela COVID-19. Na primeira parte, é tratada a evolução da concepção da saúde como um direito, inserido no âmbito da seguridade social, em diversos países, desde o final do século XIX. Na segunda, são apontadas as críticas do pensamento neoliberal aos gastos públicos com a saúde, desde a crise dos anos 1970. Já na terceira, apresentamos os argumentos que nos levam a defender que parte da saúde pública pode estar sendo ressignificada, para além do direito cidadão ou meritocrático. Entre esses argumentos, destacamos que, a crise econômica e sanitária que acompanhou o avanço da COVID-19, ao deixar claro que esta não será a última pandemia que iremos enfrentar, recolocou a saúde pública no centro da discussão, mas agora como elemento chave para a garantia da soberania nacional e da coesão social, essenciais à continuidade do processo de acumulação na mundialização do capital. Para isso, foi feita revisão da literatura de textos que colocam o acesso à saúde a partir de uma perspectiva histórica crítica e acompanhamento dos desdobramentos da crise sanitária decorrente da COVID-19.

Palavras-chave: COVID-19. Saúde pública. Universalidade. Soberania nacional. Coesão social.

Abstract: This article discusses the redefinition of a portion of public health policies in view of the new reality established by COVID-19. The first part deals with the evolution of the concept of health as a right since the end of the 19th century, within the scope of social security in several countries. The second part discusses the criticisms made by neoliberal thinking to public spending on health kicked off by the 1970 s crisis. In the third part, we defend that part of public health may be in the process of being reframed, beyond the concepts of civil rights or meritocracy. Among these arguments, we highlight that, by making it clear that this will not be the last pandemic we will face, the economic and health crisis that accompanied the advance of COVID-19 has brought back public health at the center of the discussion, now placed as a key element for the guarantee of national sovereignty and social cohesion. These are essential for the continuity of the accumulation process with the globalization of capital. To this end, this article presents a literature review that analyzes both the access to healthcare from a critical historical perspective and the monitoring of the consequences of the health crisis resulting from COVID-19.

Keywords: COVID-19. Public health. Universality. National sovereignty. Social cohesion.

\section{(c) (i)}

Artigo está licenciado sob forma de uma licença Creative Commons Atribuição 4.0 Internacional.

Este artigo é uma versão modificada do capítulo 4 do livro Pandemias, Crises e Capitalismo, editado pela editora Contexto, em abril de 2021, dos mesmos autores.

2 Pontifícia Universidade Católica de São Paulo (PUC-SP), São Paulo, SP, Brasil.

3 Universidade Paulista (UNIP), São Paulo, SP, Brasil. 


\section{Introdução}

O avanço e predomínio do neoliberalismo na ordenação da economia capitalista mundial das últimas década, intensificando tanto as cadeias globais de valor como a especialização da produção em alguns paises, mostrou-se um obstáculo importante nos primeiros meses de combate à pandemia. Em especial, houve problemas decorrentes do fato de equipamentos de saúde e de alguns tipos de medicamentos terem sua produção altamente concentrada na China e na Índia.

Exatamente neste contexto é que se observa o surgimento e a evolução da pandemia da COVID-19. As medidas emergenciais de preservação e proteção à saúde, com a exigência de oferta imediata de máscaras de proteção, de aparelhos de ventilação e de medicamentos, se depararam com o despreparo dos paises para seu atendimento imediato. Com o parque industrial no setor desativado, as demandas de importações destes produtos provenientes da China e da Índia se acumularam, evidenciando a impossibilidade destes paises ofertarem a quantidade demandada em tão curto espaço de tempo. A própria China, onde a epidemia tem início, ao adotar medidas rigorosas de contenção e de enfrentamento à COVID-19, vê sua produção reduzida emergencialmente não podendo atender o volume de solicitações de compra dos equipamentos de saúde, e a Índia, responsável pela maior parte da oferta de medicamentos a todo o mundo, vê sua capacidade de oferta constrangida por não dispor das matérias-primas para sua fabricação, provenientes quase integralmente da China.

A perda de soberania, no enfrentamento de emergências, induzida pela conformação da estrutura produtiva mundial, conduzida pelo neoliberalismo na economia capitalista, traz consigo a percepção de que certos segmentos da produção, ligados à segurança e à saúde da população, não podem ser entregues sem limitações às exigências da acumulação de capital. É neste contexto que as falas do presidente francês Emmanuel Macron, em março de 2020, ao visitar as instalações de uma empresa voltada à produção de produtos médicos e cirúrgicos, afirma que é necessário produzir mais em solo francês e europeu para assegurar a soberania nacional, e depois, em agosto de 2020, ao inaugurar uma nova fábrica do laboratório farmacêutico Seqens, na periferia de Paris, enfatizou o fato como sendo um exemplo, na prática, da "recuperação da saúde e da soberania industrial" para reduzir sua dependência à importação de medicamentos da Índia, ampliando sua produção no território nacional. Em diversos paises, esse sentimento da perda de soberania dos governos em adotar medidas emergenciais, especialmente na área da saúde, é acompanhado pela recolocação dos princípios dos direitos sociais à saúde, que deve ser tratada como um direito universal, não podendo ser entendida como um segmento a ser livremente explorado pelo capital.

Para dar conta de investigar esse processo, este artigo foi estruturado em três partes, além dessa apresentação. Na primeira, é apresentada a evolução da concepção da saúde como um direito, inserido no âmbito da seguridade social, em diversos países, desde o final do século XIX, envolvendo tanto o entendimento da saúde como um direito corporativista/meritocrático como a adoção do principio dela ser um direito básico do ser humano, seja a partir da criação do National Health Service (NHS) inglês ou mesmo pela inclusão desta concepção na Constituição brasileira, em 1988, como um direito universal e integral, garantido pelo Estado. A segunda parte trata das críticas realizadas pelo pensamento neoliberal aos gastos públicos com a saúde, desde a crise dos anos 1970. Argumenta-se que, em geral, o crescimento dos gastos com saúde está mais associado aos interesses privados associados à saúde do que devido ao fato dela ser universal. Finalmente, na terceira parte, apresentamos os argumentos que nos levam a defender que a saúde pode estar sendo ressignificada, para além do direito cidadão ou meritocrático. A saúde passa a ser elemento central, a ser promovido e assegurado pelo Estado, dada a necessidade de as classes dominantes garantirem a preservação da soberania nacional e a manutenção da coesão social em um mundo globalizado e pandêmico. 


\section{A saúde como um direito universal}

Foi um longo processo até que a saúde constituisse objeto da ação do Estado e levou ainda mais tempo para que ela fosse entendida como um direito de todos. Esse processo confunde-se particularmente com o desenvolvimento do capitalismo no século XX e com a organização dos trabalhadores em sindicatos e partidos próprios. O preceito de que a saúde é um direito de todos e um dever do Estado, tal como está escrito na Constituição brasileira, em seu artigo 196, não foi incorporado em todos os paises e nem ocorreu de forma homogênea naqueles que o fizeram.

Até o século XVIII, o próprio desenvolvimento da medicina era incipiente e os cuidados com a saúde, entendidos como os cuidados propiciados por médicos, ocorriam mediante três mecanismos: a população pobre era atendida em hospitais e hospícios, em geral administrados por organização religiosa; a população em geral, na imensa maioria rural, contava com os cuidados derivados do saber da comunidade local; e os mais ricos eram atendidos por médicos particulares, mediante pagamento.

Já no século XIX, os problemas associados às condições de higiene das fábricas e das cidades, adensadas de forma desorganizada com a industrialização e a crescente expulsão da população do campo, impôs o surgimento das primeiras políticas sanitárias desenvolvidas pelas autoridades públicas. Estas acabaram por ser institucionalizadas e tinham em vista tanto o combate e/ou prevenção das doenças transmissiveis, principalmente surtos de cólera e febre tifoide, como as condições de moradia e de locais de trabalho. Os relatórios e documentos oficiais produzidos pelos fiscais do trabalho da Inglaterra são ricos em detalhar as condições a que os assalariados fabris estavam submetidos à época. Engels e Marx trazem à luz do dia várias das situações neles descritas, tanto em $A$ situação da classe trabalhadora da Inglaterra como em O capital. É neste século, também, que a profissão médica é regulamentada. Em resumo, as políticas públicas de saúde desse periodo eram higienistas e assistencialistas, tendo o Estado ampliado a rede de hospitais voltada ao atendimento dos pobres.

Do lado dos trabalhadores, que haviam perdido suas antigas redes de proteção associadas a suas comunidades rurais, começam a ser organizadas associações de ajuda mútua com o objetivo de financiar os custos derivados dos riscos associados à industrialização, tais como acidente de trabalho e doença, mas também da velhice e mesmo a morte. Nesta última situação, tratava-se de providenciar e financiar o enterro, dado que não havia, em um primeiro momento, serviço público e gratuito para este fim. Paralelo a essas iniciativas, alguns capitalistas trataram de prover um certo nivel de proteção social a seus trabalhadores, cuidando dos doentes, fornecendo moradia (ao construir casas ao lado dos estabelecimentos) e mesmo escola às crianças. A literatura é farta em relatar essas experiências. Em "Como a burguesia resolve o problema da habitação", Engels afirma que a preocupação dos capitalistas com a moradia dos trabalhadores está relacionada à saúde dos operários, na medida em que as más condições de higiene nas habitações ocasionariam doenças que poderiam se transformar em epidemias, contagiando a própria burguesia e outros trabalhadores, o que atrapalharia o processo produtivo.

A exceção à regra é encontrada na Alemanha que, em 1883, aprovou a Lei do Seguro-Saúde dos Operários. Essa lei versava sobre o financiamento do acesso aos cuidados à saúde, incluindo o "auxílio-doença", que garantia o recebimento do salário (inicialmente, de até 1/2 salário, depois ampliado para até sua integralidade) durante o período de afastamento por doença. O financiamento era baseado em contribuições sociais, equivalente a 3\% do salário, pagas pelos trabalhadores (2/3) e empregadores (1/3), com gestão realizada por Caixas. A adesão era obrigatória a todos os operários que obtivessem uma renda anual de até 2.000 marcos alemães, com vinculação às Caixas organizadas por profissão e localidade de trabalho.

Ainstitucionalização da organização da cobertura do risco doença dos operários alemães não está dissociada da preocupação em garantir a cobertura de outros riscos. Como mostrado no Quadro 1 , 
nesse mesmo ano é incluído o risco maternidade, um ano depois, o acidente de trabalho e, seis anos depois, o risco velhice, invalidez e morte. A ação das associações mútuas dos trabalhadores também ia nesse sentido, buscando dar apoio aos riscos a que os trabalhadores estão sujeitos durante sua vida.

Quadro 1 - Ano de criação dos partidos socialistas, dos sindicatos e das primeiras leis de cobertura dos principais riscos sociais, para paises selecionados.

\begin{tabular}{|c|c|c|c|c|c|c|c|c|}
\hline \multirow[b]{2}{*}{ País } & \multirow[b]{2}{*}{ Sindicato } & \multirow[b]{2}{*}{ Partido } & \multicolumn{6}{|c|}{ Riscos } \\
\hline & & & Velhice & Invalidez & Morte & Doença & Maternidade & $\begin{array}{c}\text { Acidente de } \\
\text { trabalho }\end{array}$ \\
\hline Reino Unido & 1867 & 1900 & 1908 & 1911 & 1925 & 1911 & 1911 & 1887 \\
\hline Alemanha & 1868 & 1875 & 1889 & 1889 & 1899 & 1883 & 1883 & 1884 \\
\hline Franca & 1895 & 1905 & 1910 & - & - & 1928 & 1928 & 1898 \\
\hline Suécia & 1898 & 1889 & 1932 & 1932 & 1932 & $1891 / 1931$ & $1891 / 1931$ & 1901 \\
\hline Itália & 1906 & 1892 & 1919 & 1919 & 1919 & $1924 / 43$ & 1912 & 1898 \\
\hline Espanha & 1910 & 1879 & 1919 & 1919 & 1919 & 1942 & 1929 & 1932 \\
\hline EUA & 1876 & 1901 & 1935 & 1935 & 1935 & 1965 & nd & 1908 \\
\hline
\end{tabular}

Fontes: Security he World (1990) e Navarro (1991). Complementar no Programs Throughout the World (1990), Navarro (1991), Zinn (2002) e Enzensberger (1987). Adaptado de Marques, 1997.

O Quadro 1 permite comparar a data da fundação dos sindicatos e dos partidos dos trabalhadores com o ano de aprovação das leis referentes aos riscos sociais, indicando a importância da organização independente dos trabalhadores na primeira fase da formação da proteção social. A exceção da Alemanha no cenário europeu do século XIX não ocorreu por acaso. Deveu-se à combinação de alguns fatores importantes. Entre eles, destacam-se o fato de sua industrialização ter sido tardia e, quando ocorreu, o foi de maneira rápida, incorporando o que de mais moderno havia em termos de técnica, de modo a registrar estabelecimentos fabris de porte significativo. Seu operariado, por sua vez, é o primeiro a se organizar em partido (1875), quatro anos após a experiência da Comuna de Paris ter sido derrotada.

O século XX constitui um marco na história da construção da proteção social europeia, com reflexos em vários outros países fora da região. As condições peculiares do imediato pós II Guerra Mundial (II GM), de natureza política, social e econômica, deram sustentação à criação e ao desenvolvimento daquilo que ficou chamado de Welfare State. É nesse momento que, no campo da saúde, começaram a ser constituídos verdadeiros sistemas públicos de saúde. Embora todos esses sistemas apresentem entre si elementos semelhantes quanto à organização, à atribuição de instituições por atividades, rede de serviços e um único tipo de financiamento, a história do país e a relação do Estado com a sociedade conferem a traços próprios a cada sistema (LOBATO; GIOVANELLA, 2012).

$\mathrm{Na}$ Europa ocidental, dois tipos de modelos institucionais se desenvolveram no periodo aberto pós II GM: o institucional - redistributivo ou social-democrata, cujo exemplo maior é o NHS inglês - e o Corporativista ou Meritocrático, associado fortemente à Alemanha e França. Desde seu início, o modelo social-democrata teve como fundamento o princípio da cidadania, de modo que garantia (garante) o acesso universal à saúde, independentemente das condições financeiras de cada um. É organizado pelo Estado e financiado por impostos, em geral progressivos. Além da Inglaterra, Suécia, Dinamarca, Finlândia, Grécia, Espanha, Itália e Portugal têm sistemas públicos de saúde semelhantes. Contudo, a adesão destes três últimos países a esse tipo de sistema de saúde é mais recente. A Itália faz sua reforma em 1978 (antes o sistema era corporativo), como resultado de um amplo movimento de reforma sanitária. A reforma italiana foi grande influenciadora do processo que culminou, no Brasil, na criação do Sistema Único de Saúde (SUS). Da mesma maneira, a passagem do sistema corporativo para o universal, realizada em Portugal e na Espanha, em 1980, inscreve-se no processo aberto pela 
democratização dos paises, com a Revolução dos Cravos e a morte de Franco.

O modelo corporativista ou meritocrático tem como princípio norteador a proteção ao trabalhador e sua familia. Seu financiamento é fundado em contribuições sociais realizadas pelos trabalhadores e empregadores e o sistema pode estar organizado em Caixas de Saúde ${ }^{2}$ ou, como é o caso da França, em uma única Caixa. Além da Alemanha, também a Áustria, a França, a Holanda, a Bélgica são países que adotaram esse modelo.

Desde a crise de meados dos anos 1970, a fronteira entre esses dois modelos de sistemas públicos de saúde começou a se embaralhar, particularmente devido à ampliação da cobertura para segmentos não contribuintes ao sistema corporativista e pela entrada de impostos como reforço a seu financiamento. A nova realidade do mercado de trabalho (bem diferente dos trinta anos gloriosos), na qual a existência de significativo contingente de desempregados passou a fazer parte da realidade dos países, bem como a crescente precarização das relações salariais, certamente foram fatores decisivos na ampliação da cobertura das ações e serviços de saúde para além do critério meritocrático. Evidentemente que, com o neoliberalismo, a pressão sobre esses sistemas se fez muito forte, mas embora tenham sido incorporados alguns mecanismos que podemos dizer que têm como origem a experiência privada (aumento da participação do usuário no financiamento - "ticket moderador" - como forma de inibir a demanda considerada demasiada em alguns casos; e a instituição de orçamento rígido, entre outros), os sistemas continuam públicos nos paises aqui citados.

É importante destacarmos os fundamentos e as implicações do entendimento de ser a saúde um direito de todos, decorrente da cidadania e, portanto, um dever do Estado. Podemos dizer que a base primeira dessa compreensão está associada à Declaração dos Direitos Humanos, aprovada em 1948. na Assembleia Geral da Organização das Nações Unidas (ONU). Em dezembro de 1966, essa Assembleia aprovou a Resolução 2.200-A (XXI), alçando os direitos sociais ao nivel de direitos humanos. ${ }^{3}$

Os direitos humanos, também chamados de fundamentais, são inalienáveis, isto é, são direitos intransferiveis e inegociáveis; imprescritiveis, de modo que não deixam de ser exigiveis em razão do não uso; irrenunciáveis, pois nenhum ser humano pode renunciar à existência desses direitos; e universais, aplicados a todo ser humano independentemente da cor, raça, gênero, religião e orientação política. Os direitos sociais, integrantes dos direitos fundamentais, fazem parte daquilo que é chamado na literatura de "direitos de segunda geração".

Ao contrário dos direitos de "primeira geração", não estão centrados no indivíduo e sim no coletivo. Os direitos de primeira geração, que compreendem os direitos individuais, foram construidos ao longo dos séculos XVII e XVIII, e tratam dos direitos da pessoa humana em relação ao Estado. Compreendem direitos civis e políticos inerentes ao ser humano e oposto ao Estado (na época, visto como grande opressor das liberdades individuais. Ainda, hoje, assim entendido por alguns grupos, com destaque para alguns situados nos Estados Unidos). Incluem o direito à vida, segurança, justiça, propriedade privada, liberdade de pensamento, voto, expressão, crença, locomoção (direito de ir e vir), entre outros. Os direitos de segunda geração não estão mais baseados no individuo e determinam que o Estado faça prestação positiva em benefício da pessoa que necessite desses direitos. Estão intrinsecamente ligados à assistência social, educação, saúde, cultura, trabalho, entre outros (MACHADO; MATEUS, 2010). ${ }^{4}$

Dessa forma, o direito ao acesso aos cuidados com a saúde pode ser entendido como derivado do fato de sermos humanos. E a única instituição capaz de garantir esse acesso é o Estado, que o faria sem

\footnotetext{
2 As Caixas de Saúde são organizações geridas por representantes dos trabalhadores e empregadores, organizadas inicialmente por categoria profissional. Concedem assistência médica de acordo com sua capacidade financeira, o que cria segmentação e diferenciação dos cuidados. Historicamente, surgiram na Alemanha de Bismarck. Por isso, o modelo de saúde corporativista ou meritocrático é também conhecido como modelo Bismarckiano.

3 O Brasil ratificou essa resolução em 24 jan. 1992.

4 Há, ainda, os direitos de terceira (direitos coletivos, tais como o direito ao meio ambiente, autodeterminação dos povos, entre outros, que, de certa forma, fazem uma sintese entre as duas gerações de direitos precedentes) e da quarta geração, associado a minorias.
} 
considerar as condições de renda, a cor, o gênero, a religião, entre outros quesitos. Assim, teriamos, na saúde, o amalgama do direito à saúde, aplicado a todos, com o dever do Estado de fornecê-lo. O direito e o dever são, na saúde, inseparáveis.

O reconhecimento do acesso às ações e serviços de saúde faz parte, portanto, do avanço em matéria de políticas sociais que associamos aos trinta anos que se seguiram ao fim da II GM. Como vimos, a superação do modelo corporativo para o universal (social-democrata), ocorreu em momentos diferentes nos paises. No Brasil, o corolário desse processo foi a Constituição de 1988.

\section{O setor privado e a saúde}

Durante o período mencionado anteriormente, no qual o direito universal à saúde se moldou e os sistemas universais se desenvolveram, não esteve ausente a presença de seus críticos, que defendiam que a presença do Estado na garantia do acesso à saúde deveria ser concentrada nas faixas de renda mais baixas da população, especialmente naquelas onde a pobreza se fizesse presente. Essa visão ganha força quando da crise de meados dos anos 1970, momento em que a arrecadação tributária se reduziu e os gastos sociais aumentaram por força do desemprego expressivo. A seguir, com o crescente domínio do pensamento neoliberal - e seu consequente processo de desregulamentação da economia e questionamento do papel a ser exercido pelo Estado -, essa posição ganha força e passa a ser defendida pelos organismos internacionais, tais como Fundo Monetário Internacional (FMI) e Banco Mundial (BM).

$\mathrm{Na}$ batalha de ideias que se travou (a ainda se trava) entre os que consideram que o Estado deve apenas garantir o acesso às ações e serviços de saúde da população mais pobre de um país e aqueles que defendem o direito como universal, os primeiros fundamentavam (fundamentam) seu argumento nas causas do aumento do gasto em saúde, como proporção do Produto Interno Bruto (PIB) ao longo dos anos, comportamento que pode servisto na Tabela 1 para alguns países selecionados.

TABELA 1 - Gastos públicos em países selecionados, como percentual do PIB

\begin{tabular}{lccccccc}
\hline Pais & $\mathbf{1 9 6 0}$ & $\mathbf{1 9 6 5}$ & $\mathbf{1 9 7 0}$ & $\mathbf{1 9 7 5}$ & $\mathbf{1 9 8 0}$ & $\mathbf{1 9 9 0}$ & $\mathbf{2 0 0 0}$ \\
\hline Alemanha & 3,2 & 3,6 & 4,2 & 6,6 & 6,5 & 5,8 & 8,3 \\
Canadá & 2,4 & 3,1 & 5,1 & 5,7 & 5,4 & 6,8 & 6,2 \\
Espanha & nd & 1,4 & 2,3 & 3,6 & 4,3 & 5,2 & 5,2 \\
Estados Unidos & 1,3 & 1,6 & 2,8 & 3,7 & 4,1 & 5,6 & 5,8 \\
França & 2,5 & 3,6 & 4,3 & 5,5 & 6,1 & 6,6 & 8,0 \\
Itália & 3,2 & 4,1 & 4,8 & 5,8 & 6,0 & 5,8 & 5,9 \\
Japão & 1,8 & 2,7 & 3,0 & 4,0 & 4,6 & 4,8 & 6,1 \\
Países Baixos & 1,3 & 3,0 & 5,1 & 5,9 & 6,5 & 5,7 & 5,0 \\
Reino Unido & 3,0 & 3,4 & 4,5 & 4,3 & 5,6 & 8,2 & 8,0 \\
Suécia & 3,4 & 4,5 & 6,2 & 7,2 & 8,8 & 7,9 & 6,9 \\
\hline
\end{tabular}

Fonte: Elaborada pelos autores (2020) com dados de: OECD (1985, 2020); BM (1993); OMS (2014).

Na literatura especializada, o crescimento do gasto em saúde deve-se principalmente aos seguintes fatores: a extensão e a melhoria da cobertura que ocorreu especialmente no período chamado de Estado do Bem Estar; a maior exigência do usuário; o envelhecimento da população; a alta de preços de bens e serviços; e a introdução e desenvolvimento de técnicas mais sofisticadas na prática da assistência à saúde. 
A extensão da cobertura foi resultado da universalização do acesso à saúde, o que se traduziu na incorporação de novos segmentos populacionais, inclusive daqueles que não contribuiam, no caso de o sistema ter como base de financiamento as contribuições sociais. Já a melhoria da qualidade de cobertura foi produzida pela crescente diversificação e complexidade que assumiu a oferta pública de serviços médico-sanitários. Esses, ao longo dos anos e em alguns países, passaram a contemplar assistência odontológica, psicanalítica e terapias de alto custo. Este aspecto expressa a concretude do avanço da concepção da integralidade das ações e serviços de saúde pública num ambiente de franco desenvolvimento das técnicas da medicina.

Como sabido, o envelhecimento da estrutura etária da população, provocado pela queda da fecundidade e da mortalidade, teve impacto direto nos gastos com saúde. A população idosa tende a ter doenças crônicas, as quais exigem tratamentos prolongados e, não raras vezes, caros. Sendo assim, a curva de custos em saúde por idade tem a forma de um jota. No nascimento e nos primeiros anos de vida são mais altos, decrescem ao longo da infância e adolescência, passam a crescer com a maturidade e aumentam exponencialmente na velhice. De forma que o custo com saúde para pessoas maiores de 65 anos é três vezes maior do que os cuidados exigidos pela população entre 14 e 64 anos. Para os de mais de 75 anos, o custo é cinco vezes mais elevado (UNIVERSIDADE ESTADUAL DE CAMPINAS, 1985; Medici; Marques, 1996).

A maior exigência do usuário, apontada como um dos fatores do aumento do gasto com saúde no período do Estado do Bem-Estar, é explicada como resultado da própria melhoria do nivel de vida das pessoas. De fato, a expansão da saúde ocorreu num periodo que se caracterizou por aumentos do salário real, pela melhoria da distribuição da renda e pela democratização do acesso a informações e bens de consumo. É provável que isso tenha incentivado as pessoas e suas organizações a exigirem acesso a tratamentos mais modernos. No período subsequente, isto é, que é chamado de predominância do neoliberalismo, mesmo com a mudança da política salarial - que de aumento real passou à diminuição do salário médio da maioria dos trabalhadores -, os setores de renda mais alta da população seguem pressionando pela incorporação das tecnologias de ponta na assistência saúde.

Além disso, está mais do que comprovado que a incorporação de novas técnicas de tratamento ou de diagnóstico, bem como a prescrição de medicação cara, são em grande medida altamente definidas pelo corpo de trabalhadores da área da saúde, principalmente pelos médicos. Esse tipo de pressão pode resultar na incorporação de equipamentos sofisticados sem que tenha havido qualquer estudo da necessidade da demanda ou do custo-benefício de sua adoção. É preciso mencionar, ainda, que junto com a adoção de novas técnicas e equipamentos surgem novas especialidades. A incorporação do progresso técnico em saúde, como novas formas de diagnóstico, terapia baseada em equipamentos e medicamentos sofisticados, diferentemente do que ocorre em outros setores, não substitui trabalho por capital. Ao contrário, aumenta a necessidade de mão de obra cada vez mais complexa e especializada. Uma nova tecnologia de imagem, como scanners ou ressonância magnética, além de incorporar seu custo ao tratamento, determina o uso de operadores e médicos especializados na interpretação dos exames produzidos pela nova tecnologia.

A alta de preços de bens e serviços, muitas vezes a taxas maiores que em outros setores, reflete a inexistência de escolha por parte do usuário e do setor público no tratamento a ser realizado. Isso porque a saúde é um setor único, no qual a demanda é altamente determinada pelos médicos, pelos atendentes, entre outros profissionais da área. Daí deriva que sua estrutura de custos também é definida por esses "atores". Na melhor das hipóteses, o profissional tenderá a utilizar os recursos de última geração, na esperança de precisar seu diagnóstico e o tratamento a ser seguido. Ocorre que toda tecnologia de ponta é, por definição, cara, pois exigiu anos de pesquisa e desenvolvimento que precisam ser amortizados 
e apresenta um mercado produtor extremamente oligopolizado. Ademais, deveria ser considerado o papel da indústria de medicamentos no custo crescente dos cuidados com a saúde. Seu elevado grau de oligopólio e de controle sobre a tecnologia, via detenção das patentes, que são "renovadas" a partir de pequenas alterações nas fórmulas dos medicamentos, é, sem sombra de dúvida, um elemento que eleva o gasto com saúde. A produção de genéricos e a luta pela quebra das patentes constituem uma tentativa de fazer frente a esse monopólio.

A partir do reconhecimento desses fatores como causadores do aumento do gasto com saúde, diferentes vozes passaram a defender que o Estado se ocupasse exclusivamente dos setores mais pobres da população, deixando o restante da população resolver o acesso mediante sua renda, particularmente via filiação a planos e seguros de saúde. Para se entender o ambiente em que essa consideração começou a ser feita é preciso se considerar que, paralelo a isso, era questionada, de forma geral, a eficiência do Estado. Em outras palavras, dada a inevitabilidade do aumento do gasto em saúde, se faria necessário usar todos os recursos para garantir a eficiência do gasto e, segundo os neoliberais, o serviço público seria intrinsicamente avesso à implantação de controles e de processos avaliativos das políticas, programas e procedimentos.

Em 1994, o Banco Mundial, em sua primeira manifestação a respeito da saúde, dedica seu relatório anual a analisar e propor reformas especialmente para os "países em desenvolvimento", destacando a má alocação de recursos, o privilegiamento dos mais favorecidos, a ineficiência e os elevados custos. Entre as medidas por ele sugerida, destacam-se: redirecionamento dos gastos para programas mais eficazes, de menores custos (leia-se assistência básica) e focalizados nos pobres; diversificação e concorrência no financiamento e prestação dos serviços de saúde (isto é, a ênfase no setor privado). De fato, o documento de 1993 (que estava completamente em consonância com as diretrizes e recomendações do Consenso de Washington) considerava que a ação do Estado em matéria de saúde era residual ou complementar ao privado, voltada à população pobre e a ações de menor custo e maior eficácia. Caberia ao Estado atuar em seis áreas: a) serviços de saúde (imunização, tratamento em massa para verminoses, triagem em massa de doenças como câncer uterino e tuberculose); b) nutrição (educação nutricional, suplementação e reforço alimentar); c) fecundidade (serviços de planejamento familiar, aborto sem risco); d) tabaco e outras drogas (programas para redução do consumo de tabaco e álcool); e) meio ambiente familiar e externo (ação reguladora, controle de vetores e poluição, saneamento, políticas para melhorar o ambiente doméstico como renda e instrução); e f) AIDS (prevenção). Nessas áreas, as intervenções prioritárias seriam: a) assistência à gestante (atendimento pré-natal, no parto e pós-parto); b) serviços de planejamento familiar; c) controle da tuberculose; d) controle das DST; e e) atendimento a doenças graves comuns em crianças pequenas - doenças diarreicas, infecções respiratórias agudas, sarampo, malária e desnutrição aguda (BANCO MUNDIAL, 1993).

No caso específico do Brasil, antes mesmo do relatório mundial de 1993, o BM já havia produzido um documento de nome Brasil: novo desafio à saúde do adulto e publicado em 1991. Tratava-se de um diagnóstico do sistema de saúde brasileiro que vai completamente de encontro ao que havia sido introduzido na Constituição de 1988. Nas palavras do documento: "as realidades fiscais colidem com os sonhos de despesa alimentados pelo processo de democratização e pela Constituição de 1988" (BANCO MUNDIAL, 1991, p. 20). Nesta parte, é claramente explicitada a relação entre política social e metas macroeconômicas, na qual o gasto em saúde fica subordinado ao desempenho fiscal com vista à redução do déficit público e a facilitação do pagamento da dívida externa. E para estar de acordo com "as realidades fiscais", o SUS deveria "orientar-se especificamente para os pobres" (BANCO MUNDIAL, 1991, p. 7).

Ao primeiro relatório anual do BM, seguem-se vários outros, que são facilmente localizados em seu site. Neles, a posição não mudou, se trata de 
garantir a universalidade do acesso mediante a soma da ação do setor público dirigida aos mais pobres, com ênfase na Atenção Básica, com a ação privada, via Planos e Seguros de Saúde ou de pagamento direto do usuário.

\section{A ressignificação da saúde pública}

Uma das discussões que se abriu como resultado da pandemia da COVID-19 foi o lugar que deve ser reservado à saúde pública no contexto do capitalismo contemporâneo. O ponto de partida é o reconhecimento de que o capitalismo atual ocorre em escala global, não existindo praticamente país em que suas determinações não estejam presentes de forma dominante; e de existirem inúmeras interconexões entre os países em todos os planos da atividade humana, das quais as cadeias globais de valor constituem apenas um aspecto, de modo a constituir razões de um evento econômico, social e sanitário ficar, de maneira cada vez mais rara, restrito a seu lugar de origem. O último evento, o da COVID-19, precisou de pouco tempo para espalhar o novo coronavírus no mundo e levar a economia mundial à profunda recessão, jogando milhões de pessoas no desemprego e na pobreza.

Está fora de cogitação que o capitalismo, recuperado da pandemia, venha registrar um retrocesso no tocante $\dot{a}$ "globalização" e $\dot{a}$ interdependência entre os paises e empresas. A expansão do capital observada nas últimas décadas é decorrência da exigência de seu próprio processo de acumulação. Isso não quer dizer que não seja possivel haver um retrocesso, mas, para isso acontecer, seria necessária uma profunda destruição das relações econômicas e sociais, o que não é o caso, por pior que tenha sido o ano de 2020. Seria necessária a ocorrência de um verdadeiro cataclisma mundial ou de um longuíssimo e ininterrupto processo de entropia das relações capitalistas. Políticas protecionistas e endurecimento com relação aos imigrantes, que são apontados por alguns como sinal do enfraquecimento da globalização, seriam apenas dois entre vários outros aspectos de um mundo "fechado" e, provavelmente, não os principais.
Além da persistência da "globalização", não está descartada, em hipótese nenhuma, que essa seja a única pandemia, com essa taxa de contágio, que iremos vivenciar. Desde os anos 1990, virologistas e outros especialistas alertavam que estavam se reunindo no mundo condições que poderiam favorecer a entrada de patógenos potencialmente devastadores em nossas sociedades. Entre essas condições, destacavam: a mudança climática; a crescente proximidade humana a animais selvagens - dada a ampliação da fronteira agricola sem nenhum cuidado, que destrói as barreiras ecológicas que permitiriam a dispersão de patógenos e, assim, aumentando a interface com vetores de sua transmissão; a urbanização sem controle, gerando interface com o ambiente rural; a mudança demográfica; a globalização e o aumento impressionante da quantidade de viagens internacionais. É claro que essas duas últimas condições constituiriam, a rigor, o que favoreceria a rápida disseminação do patógeno.

Entre os especialistas, há quem conceda principalidade a um dos fatores, tal como Rob Wallace (2020), que considera que os vírus recentes, neles incluida a COVID-19, tem como origem o avanço mais intenso do agronegócio nos sistemas naturais, mais especificadamente relacionada à atividade da pecuária, criando brechas nos ecossistemas e entre as espécies. Talvez o mais prudente seja considerar que a probabilidade de enfrentarmos um novo patógeno devastador é dada pelo conjunto das condições, as quais foram criadas pelo próprio homem sob o capitalismo ou que são resultado da própria ação humana em sua constante busca por produzir cada vez mais. Além disso, ele busca ocupar territórios virgens ou selvagens ainda disponíveis no planeta, sem se preocupar com que tipo de relação está estabelecendo entre a natureza e a sociedade que se estrutura com base nos princípios da reprodução ampliada do capital.

A pandemia da COVID-19, custou caro para os "negócios". Além dos óbitos que provocou, paralisou as atividades econômicas e, por isso, afetou o lucro e a reprodução do capital. Este não pode ficar ao sabor das determinações e consequências 
de novas pandemias do tipo da COVID-19. Como é improvável que, no curto prazo, as condições que resultaram na exposição a pandemias sofram mudanças e, se algo mudar, não será significativo, é preciso que os paises estejam preparados para fazer frente a ela ou para, pelo menos, reduzirem seu impacto. As pandemias, sob a mundialização do capital, tornaram-se questão de soberania nacional e de coesão social. ${ }^{5}$

Além da manifestação do presidente da França, Emmanuel Macron, mencionada na Introdução desse artigo, a respeito da posição estratégica que parte da indústria de saúde tem num cenário pandêmico e que se faz necessário não ficar dependente da importação de equipamentos da China, destaca-se o posicionamento da chanceler alemã, Angela Merkel. Essa, em 5 de setembro de 2020, anunciou a injeção de quatro bilhões de euros (até o final de 2026) no fortalecimento da saúde pública, com o objetivo de contratar cinco mil postos de trabalho para médicos, especialistas e profissionais administrativos do serviço público de saúde, e para investir na digitalização (MERKEL..., 2020).

Estes dois exemplos, distantes no tempo por alguns meses, mostram como a pandemia recolocou a saúde no centro da preocupação governamental de alguns paises. A experiência vivida em 2020 mostrou que a especialização ocorrida com a produção de equipamentos de saúde na China, fruto do processo de mundialização do capital, tornou as nações, no todo ou na parte, dependente da pronta resposta desse país quando do aumento abrupto da demanda. Os paises que não tinham desmontado totalmente sua indústria de equipamentos médicos no periodo anterior, sairam-se melhor do que os outros no enfrentamento da pandemia. A hipótese que estamos defendendo é que manter no território nacional a produção desses equipamentos é uma questão estratégia, que diz respeito à soberania nacional.

É mais dificil que os países se contraponham ao grau de oligopolização da indústria de medicamentos, à política de patentes e à especializa- ção dos princípios ativos de medicamentos, cuja produção é altamente concentrada na Índia. Em um mundo "globalizado" e em momentos de pandemia, torna-se evidente que a tecnologia associada à produção desse ou daquele medicamento (especialmente de vacinas) não pode ser apropriada de forma privada, devendo estar disponivel para o conjunto da humanidade. $O$ direito à vida, a que todos em tese temos, faz do acesso à saúde um direito inconteste, o que implica a disponibilização dos recursos materiais e humanos para sua concretude. Nacionalizar (palavra não mais usada atualmente) ou estatizar a indústria de medicamentos, é uma necessidade crescente, mas insuficiente. Essa ação, que resultaria em uma ruptura com relação à estratégia hoje adotada pelas empresas na pesquisa e desenvolvimento de novos medicamentos, por exemplo, precisaria ser completada por uma coordenação orquestrada no plano mundial. Uma estatização, considerando os governos existentes e a correlação der forças entre as classes, está descartada. Já seria um grande avanço se os Estados promovessem uma regulação estreita dessa indústria, inclusive fazendo frente a sua oligopolização.

Estudos de organismos internacionais como a Organização das Nações Unidas (ONU), Organização Mundial da Saúde (OMS), Organização Internacional do Trabalho (OIT) e CEPAL apontam para a urgência de revisão das políticas de saúde, sugerindo modelos universais de acesso igualitário, como medida fundamental para um controle eficaz da pandemia. Em conjunto com as medidas imediatas que foram tomadas para sustentação da renda, manutenção dos empregos, e atenção em saúde, vem sendo apontado o reconhecimento da saúde como um direito humano e bem público que deve ser garantido pelo Estado. O debate sobre as condições estruturais da saúde indica a importância para o fortalecimento da saúde pública, e a consolidação de sistemas de proteção universais e integrais (CEPAL, OIT, 2020). A contrapartida da

\footnotetext{
5 Para Durkheim (1973), a coesão social se estabelece pela ação cooperada que se desenvolve a partir da existência de um quadro normativo e um sistema de crenças e valores compartilhados pelos individuos de uma comunidade. Para o autor, todo lugar em que se forma um grupo, forma-se também uma disciplina moral que rege as relações ali estabelecidas.
} 
inexistência de um sistema de saúde universal foi, como nos Estados Unidos, constatar que os segmentos sem cobertura privada foram os mais afetados na pandemia da COVID-19.

\section{Considerações finais}

Afora essa questão do acesso, há outra no mesmo plano que é a soberania nacional. Trata-se de que o Estado tenha o controle das atividades chave da área da saúde para fazer frente a pandemias como a da COVID-19 em função da necessidade de as classes dominantes manterem a coesão social. Fissuras na coesão social geram processos de ruptura institucional e política, colocando em risco a continuidade da dominação das classes dominantes sobre as subalternas. Na hipótese de contaminação completamente sem controle e de uma taxa de mortalidade considerada inaceitável pela sociedade, ao que se somaria perda de emprego e renda e quebra dos laços sociais e econômicos, a perda de coesão social fica colocada como inevitável, abrindo-se um periodo intenso de lutas, cujo resultado é incerto.

Em nome dos "negócios" (ou de "lucros adequados") e de manter a coesão social, embora apresentada na roupagem de evitar óbitos e que os sistemas de saúde entrem em colapso, governos e mesmo organismos internacionais estão recolocando a centralidade da saúde pública e a reocupação em manter parte da indústria da saúde no território nacional. É a isso que chamamos de "ressignificação da saúde". A política de saúde adotada em um país deixa de ser apenas resultado do embate do princípio da cidadania e da meritocracia.

Evidentemente que a incorporação desse significado estratégico da saúde pública (ou de parte dela) é (será) diferenciada entre os países, a depender do entendimento da própria importância atribuida à pandemia por parte dos governantes, das classes dominantes e dos representantes das instituições do Estado. Nesse sentido, o caso brasileiro apareceria como seu oposto, quando em particular o governo central se omitiu ou mesmo se negou a coordenar as ações necessárias para se contrapor ao avanço da COVID-19.

\section{Referências}

BANCO MUNDIAL. Salud: documento de política sectorial. Washington, D.C: Banco Mundial, 1975.

BANCO MUNDIAL Brasil: novo desafio à saúde do adulto. Washington, D.C.: Banco Mundial, 1991. (Série de estudos do Banco Mundial sobre paises).

BANCO MUNDIAL. Informe sobre el Desarrollo Mundial 1993: Inverter en Salud. Washington: Banco Mundial, 1993. Disponivel em: http://documents1.worldbank.org/ curated/pt/259121468340250256/pdf/341290spanish. pdf. Acesso em: 20 nov. 2020.

COMISSIÓN ECONÔMICA PARA AMÉRICA LATINAY EL CARIBE; ORGANIZACIÓN INTERNACIONAL DEL TRABAJO. El trabajo en tiempos de pandemia: desafios frente a la enfermedad por coronavirus (COVID-19). Coyuntura Laboral en América Latina y el Caribe, Santiago, n. 22, 2020. Disponivel em: https://repositorio.cepal.org/ bitstream/handle/11362/45557/4/S2000307_es.pdf. Acesso em: 29 nov. 2020.

DURKHEIM. E. Da divisão do trabalho social. In: RODRIGUES, J. A. (org.). Os pensadores: Émile Durkheim. Rio de Janeiro: abril, 1973. p. 1-70. (Coleção Os Pensadores).

EMMANUEL Macron: Rebâtir notre souveraineté nationale et européenne. En Marche, Paris, 31 mar. 2020 Disponivel em: https://en-marche.fr/articles/actualites/macron-souverainete-nationale-europeenne. Acesso em: 30 nov. 2020.

ENGELS, F. Como a burguesia resolve o problema da habitação. In: KARL, M.; ENGELS, F. Obras escolhidas. Lisboa: Edições Avante, [2006]. Disponivel em: https:// www.marxists.org/portugues/marx/1873/habita/ capoz.htm. Acesso em: 20 nov. 2020

Enzensberger, H. M. O curto verão da anarquia. São Paulo, Companhia das Letras, 1987.

LOBATO, L. V. C.; GIOVANELLA, L. Sistemas de saúde: origens, componentes e dinâmica. In: GIOVANELLA, L. et al. (org.). Politicas e sistema de saúde no Brasil. 2. ed. Rio de Janeiro: Fiocruz, 2012. p. 89-119. http://dx.doi. org/10.7476/9788575413494

MACHADO, D. H. G.; MATEUS, E. N. Breve reflexão sobre a saúde como direito fundamental. Âmbito Jurídico, São Paulo, v, 13, n. 83, dez. 2010. Disponivel em: http:// www.ambitojuridico.com.br/site/?n_link=revista_artigos_leitura\&artigo_id=8747\&revista_caderno=9. Acesso em: 19 nov. 2020

MARQUES, R. M. A proteção social e o mundo do trabalho. São Paulo: Bienal, 1997

MEDICl, A. C.; MARQUES, R. M. Sistemas de custos como instrumento de eficiência e qualidade dos serviços de saúde. Cadernos Fundap, São Paulo, v. 19, p. 47-59, jan./abr. 1996.

MERKEL anuncia pacote bilionário para a Saúde. Deutsche Welle, Alemanha, 8 set. 2020. Disponivel em https:// www.dw.com/pt-br/merkel-anuncia-pacote-bilion\%C3\%A1rio-para-a-sa\%C3\%BAde/a-54857309. Acesso em: 30 nov. 2020 
NAVARRO, V. Produção e Estado de bem-estar. O Contexto Político das Reformas. Lua Nova, São Paulo, n. 28/29, 1991. p. 157-200. Disponivel em: https://www. scielo.br/j/ln/a/Va6bGNnJVTSPKW8FtcTXzLn/?lan$\mathrm{g}=\mathrm{pt} \#$ Acesso em: 30 nov 2020

Organisation for Economic Co-operation and Development. Measuring health care, 1960-1983 - expenditure, costs, and performance. Paris: OECD, 1985.

Organisation for Economic Co-operation and Development. 2020. Data by theme, Paris. Disponivel em: https://stats.oecd.org/Index.aspx?DatasetCode=HEALTH_STAT\#. Acesso em: 8 dez. 2020

ORGANIZACIÓN MUNDIAL DE LA SALUD. Estadisticas Sanitárias Mundiales. Genebra: OMS, 2014.

UNIVERSIDADE ESTADUAL DE CAMPINAS. Despesas públicas e programas sociais. Relatório da pesquisa $A$ crise internacional e as politicas sociais: uma proposta de análise comparada. Campinas: Convênio Unicamp/ Nepp - Fundap, 1985

WALLACE, R. Pandemia e agronegócio: doenças infecciosas, capitalismo e ciência. São Paulo: Editora Elefante \& Igrá Kniga, 2020.

ZINN, Howard. Une histoire populaire des États-Unis. Marseile: Agone, 2002.

\section{Rosa Maria Marques}

Doutora em Economia de Empresas pela Fundação Getúlio Vargas (FGV), em São Paulo, SP, Brasil. Professora titular do Departamento de Economia e do Programa de Estudos Pós-graduados em Economia Política da Pontifícia Universidade Católica de São Paulo (PUC-SP), em São Paulo, SP, Brasil; líder do Grupo de Pesquisa Política para o Desenvolvimento Humano e ex-presidente da Sociedade Brasileira de Economia Política (SEP) e da Associação Brasileira de Economia da Saúde (ABrES).

\section{Marcel Guedes Leite}

Doutor em Economia de Empresas pela Fundação Getúlio Vargas (FGV), em São Paulo, SP, Brasil. Professor assistente doutor do Departamento de Economia da Pontificia Universidade Católica de São Paulo (PUC-SP), em São Paulo, SP, Brasil. Lider de equipe do grupo de pesquisa Investigação Temática em Economia e vice-lider do grupo de pesquisa Politicas para o Desenvolvimento Humano, ambos na PUC-SP. Membro do grupo de análise de conjuntura da CNBB e analista relator da CTAA/INEP/MEC.

\section{Marcelo Álvares de Lima Depieri}

Doutor em Ciências Sociais pela Pontificia Universidade Católica de São Paulo (PUC-SP), em São Paulo, SP, Brasil. Professor titular de economia da Universidade Paulista (UNIP), em São Paulo, SP, Brasil.

\section{Endereço para correspondência}

Rosa Maria Marques/ Marcel Guedes Leite

Pontifícia Universidade Católica de São Paulo

Rua Monte Alegre, 948

Edificio Reitor Bandeira de Melo, Sala 122 A

Perdizes, 05014-901

São Paulo, SP, Brasil

Marcelo Álvares de Lima Depieri

Universidade Paulista

Avenida Marquês de São Vicente, 3001

Mezanino, sala dos professores

Água Branca 05037-040

São Paulo, SP, Brasil

Os textos deste artigo foram revisados pela Poá Comunicação e submetidos para validação do(s) autor(es) antes da publicação. 